\title{
Dynamics Shaping Access to Reproductive Health Services in Peri-Urban Yangon, Myanmar: A Multi-Methods Study
}

\author{
Grace Sheehy ${ }^{1,2}$, Yadanar Aung ${ }^{3}$, Cari Sietstra ${ }^{2} \&$ Angel M. Foster ${ }^{1,2}$ \\ ${ }^{1}$ Faculty of Health Sciences, University of Ottawa, ON, Canada \\ ${ }^{2}$ Cambridge Reproductive Health Consultants, Cambridge, MA, USA \\ ${ }^{3}$ National Young Women's Christian Association of Myanmar, Yangon, Myanmar \\ Correspondence: Angel M. Foster, DPhil, MD, AM, University of Ottawa, 1 Stewart Street 312-B, Ottawa, ON., \\ K1N6N5, Canada. Tel: 1-613-562-5800 ext 2316. E-mail: angel.foster@uottawa.ca
}

Received: February 1, 2016 Accepted: March 1, 2016 Online Published: March 23, 2016

doi:10.5539/gjhs.v8n11p194 URL: http://dx.doi.org/10.5539/gjhs.v8n11p194

\begin{abstract}
Purpose: The purpose of our study was to explore and identify the reproductive health needs of women of reproductive age living in peri-urban Yangon, a dynamic series of townships on the periphery of Myanmar's largest city. Specifically, we sought to identify the availability and accessibility of reproductive health services and products, as well as potential avenues for improving the delivery and accessibility of services. Our overall study focused on maternal health, delivery care, contraception, abortion and post-abortion care. In this paper we focus specifically on the dynamics shaping access to reproductive health services.

Principal Results: Our findings suggest that barriers to access specific to both urban and rural settings converge in peri-urban Yangon and create significant challenges for service delivery organizations to reach this population, and for this population to reach health care facilities. While contraceptives are relatively affordable and accessible, non-evidence based fears of side effects, including significant and noticeable weight gain, illness, organ damage and infertility, hinder consistent use among peri-urban women. Finally, our findings suggest that unmarried women and young women are largely excluded from reproductive health care and services, and face considerable barriers to access, including discrimination from providers.
\end{abstract}

Major Conclusions: Our findings illustrate that despite an overarching availability of reproductive health services in peri-urban Yangon, a variety of geographic, socio-economic, information and socio-cultural barriers to access persist and there remains a dearth of services tailored to young and unmarried women. The peri-urban population requires a unique and tailored service delivery approach.

Keywords: Burma, contraception, Myanmar, reproductive health, service provision

\section{Introduction}

The country of Myanmar is experiencing a period of considerable growth and change. Long ruled by a military dictatorship, Myanmar was isolated from much of the world until the 2010 elections installed a nominally-civilian elected government. That administration enacted a series of reforms, including the release of political prisoners, increased investment in infrastructure, and eased media restrictions (World Bank, 2015; Hlaing, 2012). However, the military remains powerful and the country's long history of violence, forced labor, displacement and imprisonment is recent, continues to affect population health, and remains ongoing in parts of the country (Sietstra, 2012; Mullany et al., 2008). Although national spending on health has increased substantially in recent years, health outcomes across the country are varied and in many regions remain poor. Life expectancy is the lowest among the members of the Association of Southeast Asian Nations (ASEAN), and there are significant regional disparities in health indicators, including immunization coverage, and infant, maternal and child health (World Bank Group, 2014; IHLCA, 2011).

Reproductive health indicators are consistent with these overarching health dynamics and reflect significant regional and geographic disparities. Information about reproductive health is limited; reliable national statistics are difficult to access and conflict-affected areas have long been omitted from most datasets that are otherwise national in scope (Department of Population, 2014; Ministry of Health \& UNICEF, 2011; Ministry of Immigration and Population \& UNFPA, 2009). The isolationist policies of the military hindered data collection 
in the country for nearly half a century and thus there is little evidence to inform policy, programs, and donor spending. However, the best available evidence suggests that there are significant unmet reproductive health needs throughout the country.

The age of marriage for women and the total fertility rate have steadily increased and decreased, respectively, in recent years, a remarkable feat given the lack of government intervention in those domains. Other reproductive health indicators have witnessed far less improvement. The national maternal mortality ratio (MMR) is currently one of the highest among ASEAN countries, estimated at 200 deaths per 100,000 live births (World Bank, 2013), and the MMR is estimated to be four to five times higher in conflict affected regions (Burma Medical Association, National Health and Education Committee \& Back Pack Health Worker Team, 2010; Back Pack Health Worker Team, 2006). Deliveries attended by a skilled birth attendant have increased considerably, reaching 78\% in 2010 (World Bank Group, 2014). In urban settings, women are increasingly choosing institutional deliveries over home deliveries; about half of all urban women experienced their last delivery in a health facility (Ministry of Immigration and Population \& UNFPA, 2009).

In Myanmar, abortion is severely legally restricted such that the procedure can only be performed to save the life of the woman and this exception is narrowly interpreted (Ba-Thike, 1997). While the leading cause of maternal mortality at the national level is post-partum hemorrhage, at least $10 \%$ of maternal deaths are directly attributable to unsafe abortion; in conflict-affected parts of the country, as many as half of maternal deaths are due to unsafe abortion (Hobstetter et al.. 2012; UNFPA. 2010; Ba-Thike, 1997). A range of contraceptive methods, including progestin-only emergency contraceptive pills (ECPs) and long acting reversible contraception (LARC), are available in Myanmar. In 2010, the country's contraceptive prevalence rate was 46\%, a substantial increase from the early 1990s (Ministry of Health \& UNICEF, 2011). The most recent studies suggest that the majority of contracepting women use modern methods of contraception and one third of all contraceptive users use the hormonal injection (Ministry of Health \& UNICEF, 2011). Studies in eastern Myanmar and Mandalay have highlighted significant barriers to accessing reproductive health services, particularly for conflict-affected populations and adolescents (Hobstetter et al., 2015; Thin Zaw et al., 2013; Hobstetter et al., 2012; Thin Zaw et al., 2012). Previous studies have also identified the challenges in providing services for mobile, migrant, and conflict-affected populations in various parts of the country and the considerable unmet reproductive health needs of internally displaced populations (Gedeon et al., 2015; Hobstetter et al., 2012; Mullany et al., 2008a; Mullany et al., 2008b).

Although these studies present an overall picture of reproductive health in Myanmar, the need for more data to inform policy, programs, and funding priorities is pressing. In addition to the shortage of information about specific populations, a dearth of information exists about women's experiences with and perceptions of reproductive health services. Further, very little is known about reproductive health among migrant communities, a rapidly growing population in the country. Rural populations are increasingly migrating to urban centers, like Yangon, in the hope of finding better economic opportunities. Rents in Yangon are increasing exponentially, making the city unaffordable, especially for the poor (Brook, 2014; Tun, 2014; Vallikappen \& Thakur, 2013). As a result, migrants are concentrated in growing slum settlements on the periphery of the city. Donors, policy-makers, and government agencies are increasingly interested in working and investing in these townships, but lack evidence to guide these efforts.

\subsection{Study Area}

Yangon is Myanmar's largest city and former capital and has a population of approximately 7.35 million (Department of Population, 2014). The city is divided into more than 30 townships that extend into the surrounding countryside and is rapidly expanding, largely due to an influx of rural migrants. There is a dearth of data on motivations for migration to Yangon; anecdotal evidence suggests that migration to the city is likely to be largely motivated by economic opportunities, although the influence of social networks, conflict, relatives, and lifestyle may also represent important considerations (Macdonald \& Thiha Cho, 2016; Chaw, 2003; De Jong \& Fawcett, 1981). Many migrants-often poor, separated from families and social networks, and with inconsistent, unreliable wages-are increasingly settling in the cheaper townships on the periphery of the city. Although the Myanmar government does not have official criteria to classify townships as either urban or rural, this set of townships is locally known as "peri-urban Yangon." Generally, peri-urban spaces inhabit a continuum between urban and rural spaces, positioned on the "urban fringe" and displaying characteristics of both urban and rural environments (Marshall et al., 2009). While a proximity to an urban center is somewhat implied, peri-urban spaces comprise a unique set of demographic and socioeconomic characteristics which distinguish them beyond geographic location (Allen, 2010; Marshall et al, 2009; Iaquinta \& Davila, 2002; Drescher, 2000). Peri-urban areas can be characterized by rising population density, slums, poor regulation and provision of public services, 
urban proximity, and values or traditions imported from rural settings, among other factors (Marshall et al., 2009). The term "peri-urban" can also be understood as a process or "flow", focusing on broader structural or social change and the movement of resources and ideas, as much as a geographic space (Marshall et al., 2009). In the context of peri-urban Yangon, the region is most often described by local stakeholders and actors as a place, but also encompasses a broader process of urban change and growth. This study uses the term peri-urban to focus on a specific place, but also a set of characteristics and processes that describe a population and their health.

Because there are no official definitions of urban, rural, and peri-urban in Myanmar, to clearly delineate the study area and more formally classify Yangon's townships we developed a set of criteria based on the international literature, anecdotal evidence, and extensive conversation with stakeholders. We classified a township as peri-urban if it is characterized by poor infrastructure, a large number of slum settlements, and a highly mobile population that largely engages in daily wage labor. Recognizing that these criteria do not necessarily define an entire township and that differences exist both within and between townships, we identified nine townships that could be broadly categorized as peri-urban: Hlaing Thar Yar, Insein, Mingaladone, North Dagon, North Okkalapa, Shwe Pyi Thar, South Dagon, Thar Gay Ta, and Thin Gan Gyun (Figure 1). These townships were the focus of our study and, according to the Yangon Directory (2013), contain a total of 575 health service delivery points, as presented in Table 1 .

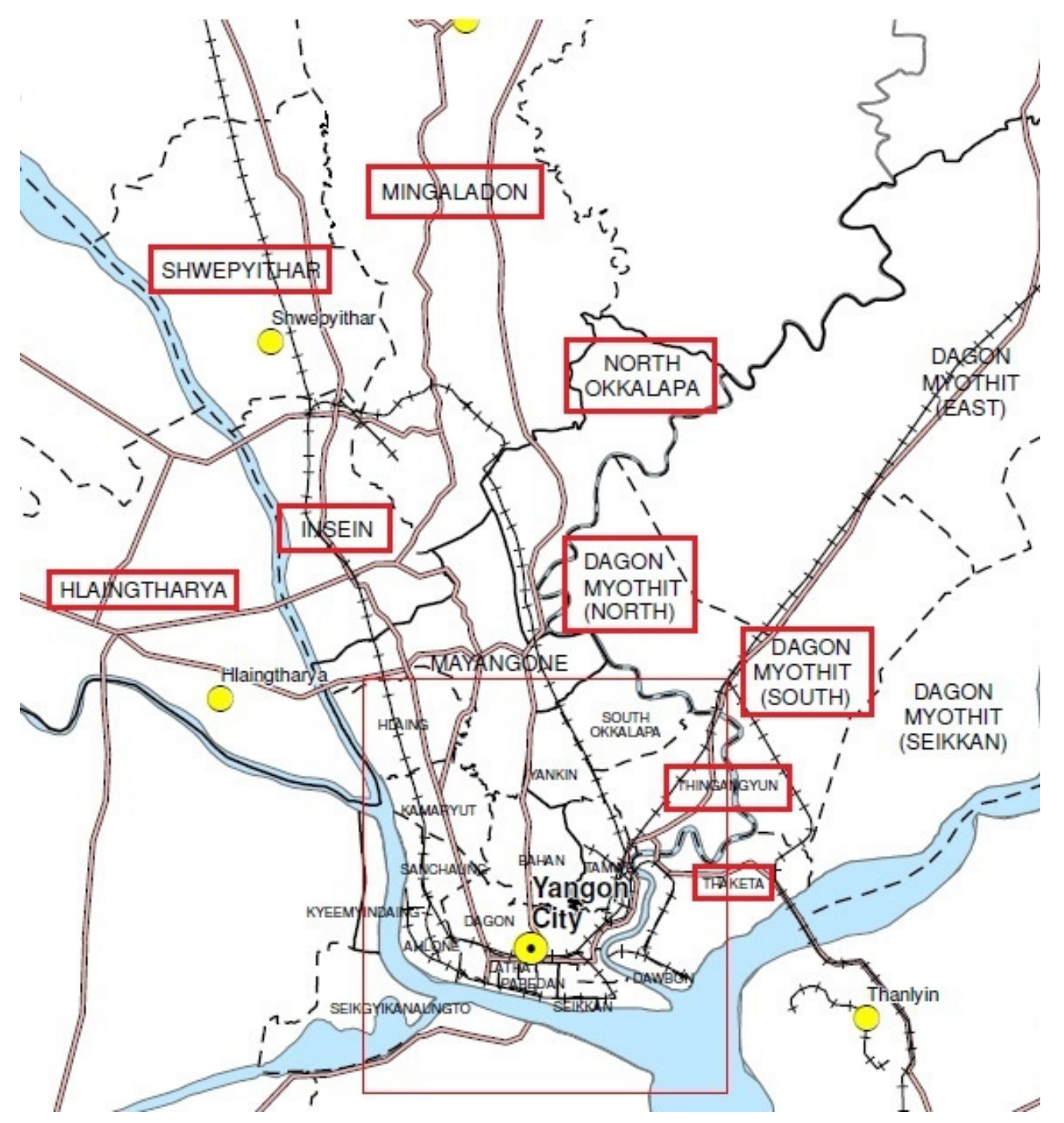

Figure 1. Map of Yangon, Myanmar, with peri-urban townships indicated

Source: Myanmar Information Management Unit (2012). Yangon Region. 
Table 1. Health service delivery points in peri-urban Yangon townships

\begin{tabular}{llllll}
\hline Township & $\begin{array}{l}\text { Population } \\
\text { (2014) }\end{array}$ & Public Hospitals & Private Hospitals & Private Clinics & $\begin{array}{l}\text { Township } \\
\text { Departments }\end{array}$ \\
\hline Hlaing Thar Yar & 686,827 & 1 & 2 & 88 & 1 \\
Insein & 305,670 & 3 & 3 & 77 & 1 \\
Mingaladone & 332,520 & 2 & 1 & 31 & 2 \\
North Dagon & 203,883 & 0 & 4 & 43 & 1 \\
North Okkalapa & 332,869 & 2 & 5 & 99 & 1 \\
Shwe Pyi Thar & 343,270 & 1 & 0 & 33 & 0 \\
South Dagon & 371,579 & 1 & 0 & 50 & 0 \\
Thar Gay Ta & 220,447 & 1 & 0 & 69 & 1 \\
Thin Gan Gyun & 209,301 & 1 & 2 & 48 & 1 \\
Total & $3,006,366$ & 12 & 17 & 538 & 8
\end{tabular}

Sources: Yangon Directory Group 2013; Department of Population 2014.

\subsection{Objectives}

Motivated by this context, the purpose of our study was to explore and identify the reproductive health needs of women of reproductive age (16-49) residing in the townships of peri-urban Yangon. We also wanted to identify the availability and accessibility of reproductive health services and products, as well as potential avenues for improving the delivery and accessibility of reproductive health services. The overall study focused on maternal health and delivery care, contraception, including emergency contraception and LARC methods, abortion, and post-abortion care. In this paper we focus specifically on the dynamics shaping access to reproductive health services.

\section{Methods}

\subsection{Data Collection}

Our study design is based on a multi-methods assessment reported in Separated by Borders, United in Need: An assessment of reproductive health on the Thailand-Burma border (Hobstetter et al., 2012). Our multi-disciplinary project team conducted data collection in the summer of 2014 in Yangon. We used a variety of data collection techniques, including key informant interviews, focus group discussions with providers and women of reproductive age, and surveys of representatives from providing facilities and peri-urban women, to explore service delivery, accessibility, and utilization.

We conducted 18 key informant interviews with representatives from non-governmental organizations (NGOs), community-based organizations (CBOs), and governmental agencies working in the field of sexual and reproductive health in all nine peri-urban townships. We identified key informants through the study team's networks, internet searches, and referrals from early participants. Using a guide developed specifically for this study, our domains of inquiry included organizational scope, perceptions of reproductive health in peri-urban Yangon, and potential avenues for improving reproductive health outcomes. GS, a Canadian master's student, conducted all semi-structured interviews, which averaged 60 minutes and were audio-recorded, in English and formally memoed after each encounter. All participants were sufficiently proficient in English to participate in an interview.

We also conducted and audio-recorded seven focus group discussions (FGDs). We held two FGDs with providers working in peri-urban Yangon: one Burmese-language discussion with hospital-based midwives in Insein township $(\mathrm{n}=4)$ and one English-language discussion with doctors working in a variety of clinical settings $(\mathrm{n}=5)$. We recruited participants with the help of a local $\mathrm{CBO}$ and providers represented six different organizations working in the peri-urban townships of Insein, North Okkalapa, and Hlaing Thar Yar. Our health service provider FGDs explored participants' experiences working in the field of reproductive health in peri-urban Yangon and averaged one hour. We also held five Burmese-language FGDs with women $(n=27)$ currently residing in peri-urban Yangon who we recruited with the assistance of three NGOs and CBOs. Our discussions explored women's perceptions of reproductive health in their townships, opinions regarding service 
accessibility, and recommendations for improving information and services. We offered participants lunch and 5,000 kyat (USD5) to cover travel and other costs. YA, a Burmese medical doctor with extensive experience conducting FGDs, facilitated all discussions. She was assisted by GS, who took extensive notes during the discussion and formally memoed afterward. YA and GS debriefed immediately after each discussion to both reflect on the content and dynamics as well as begin the analytic process of identifying emerging themes.

In order to gain a more in-depth understanding of the service delivery dynamics in the peri-urban Yangon region we conducted a service mapping exercise in North Okkalapa and Hlaing Thar Yar. Although both townships are considered peri-urban, they differ considerably in infrastructure, population, location and history; North Okkalapa is the larger of the townships, closer to the city centre and with a significant population of government employees. Hlaing Thar Yar is located further from the city centre and is a former satellite town amalgamated into Yangon and is populated predominantly by daily wage laborers and factory workers. In addition to noting the locations of service delivery points, we also conducted on-site surveys with representatives from 27 facilities, including private clinics $(n=16)$ and hospitals $(n=9)$. Using the Yangon Directory as a guide, GS and YA randomly selected facilities for inclusion and visited them during two days of travel through the township, purposively visiting different facility types. None of the facilities we surveyed were specialized reproductive health clinics. The orally-administered surveys allowed us to capture information about the facility, affiliated health service providers, catchment area, and patient population, as well the availability and cost of reproductive health services.

Finally, we conducted a short Burmese-language reproductive health survey with a convenience sample of 147 women residing in peri-urban Yangon. We administered the survey in order to get a snapshot of a group of peri-urban women's reproductive health knowledge and experiences. The Burmese-language survey asked women affiliated with the National YWCA's Microfinance Program general reproductive health questions, including those centered on contraceptive use, pregnancy history, and abortion. We summarize our methods of data collection in Table 2.

Table 2. Data collection methods

\begin{tabular}{|c|c|c|c|}
\hline Method & Sample & Number & Characteristics \\
\hline $\begin{array}{l}\text { Key informant } \\
\text { interviews }\end{array}$ & $\begin{array}{l}\text { Experts working in the } \\
\text { field of reproductive } \\
\text { health in Yangon }\end{array}$ & 18 & $\begin{array}{l}\text { Representatives from a range of local and international } \\
\text { reproductive health organizations with backgrounds in medicine } \\
\text { and public health }\end{array}$ \\
\hline \multirow{2}{*}{$\begin{array}{l}\text { Focus group } \\
\text { discussions }\end{array}$} & $\begin{array}{l}\text { Adult women living in } \\
\text { peri-urban Yangon }(n=27)\end{array}$ & 5 & $\begin{array}{l}\text { Women ages } 21-45 \text { representing a range of backgrounds, jobs, } \\
\text { and experiences, hailing from six of nine peri-urban townships. A } \\
\text { total of } 27 \text { women participated in } 5 \text { focus group discussions. }\end{array}$ \\
\hline & $\begin{array}{l}\text { Doctors and midwives } \\
\text { working in peri-urban } \\
\text { Yangon }(n=9)\end{array}$ & 2 & $\begin{array}{l}\text { Doctors worked or volunteered in clinics and hospitals in } \\
\text { peri-urban Yangon. Midwives all worked in one private } \\
\text { peri-urban hospital. A total of } 9 \text { doctors and midwives } \\
\text { participated in } 2 \text { focus group discussions. }\end{array}$ \\
\hline Surveys & $\begin{array}{l}\text { Adult women participating } \\
\text { in the YWCA's } \\
\text { Microfinance program }\end{array}$ & 147 & $\begin{array}{l}\text { Women representing a range of ages, backgrounds and } \\
\text { experiences, hailing from six of nine peri-urban townships. }\end{array}$ \\
\hline $\begin{array}{l}\text { Service } \\
\text { mapping }\end{array}$ & $\begin{array}{l}\text { Clinics and hospitals } \\
\text { operating in two } \\
\text { peri-urban townships }\end{array}$ & 27 & $\begin{array}{l}\text { Service delivery points included private clinics, private hospitals, } \\
\text { and public hospitals. }\end{array}$ \\
\hline
\end{tabular}

\subsection{Data Analysis}

Using transcripts (translated to English), notes, and memos, we analyzed the key informant interviews and FGDs for content and themes, using both a priori (pre-determined) categories and codes based on the research questions and inductive codes that emerged from the data. This was an iterative process in that analysis occurred simultaneous to data collection, and we collected data until we were confident we had achieved thematic saturation (Elo \& Kyngäs, 2008; Deniz \& Lincoln, 2005). We used ATLAS.ti to manage our qualitative data. Regular team meetings guided the identification of themes and interpretation of the findings and we resolved differences by discussion. We entered survey responses into Microsoft Excel and analyzed these data with 
descriptive statistics. We analyzed each component of the project separately and in the final analytic phase we combined the findings, with specific attention to concordant and discordant results. This triangulation of multiple data sources allowed us to identify prominent themes which we present in the results section.

\subsection{Ethics}

We received approval for this study from the Research Ethics Board (REB) at the University of Ottawa (File \#H02-14-03). The Board of Directors of the National YWCA of Myanmar also reviewed and approved the study protocol. In order to protect the confidentiality of our participants we have removed or masked all personally identifying information throughout this article.

\section{Results}

\subsection{Participants}

Our participants represented a range of backgrounds, ages, and experiences. Women in our FGDs $(n=27)$ lived in six of the nine peri-urban townships and ranged in age from 21 to 45 . Slightly more than half $(n=15)$ were unmarried. Our participants worked as daily laborers, street-side vendors, tailors, and housewives, and many worked long days making wages they often characterized as low. In some of our FGDs, as many as half of participants had migrated from rural settings to peri-urban Yangon.

Survey respondents also resided in six peri-urban townships, with the majority living in North Okkalapa (50\%) and Hlaing Thar Yar (33\%). One-quarter identified as hailing from a rural area of Myanmar. Respondents were largely older than FGD participants; just over half were 40 or above and the majority were married. More than half (59\%) were employed and the majority (78\%) had completed some middle school or high school.

\subsection{Urban and Rural Barriers to Access Converge in Peri-Urban Yangon}

They have to travel; they have to walk one hour...and they have no proper transportation...So it is very difficult to travel for the health services. It is one of the constraints for them. (Key informant, June 2014)

The townships of peri-urban Yangon begin outside the downtown core and extend far into the surrounding countryside; thus, access to services varies considerably both within and between townships. However, given the overall relative proximity to the urban center of Yangon, health services are plentiful compared to rural parts of the country. Most peri-urban townships have one or two public hospitals, while private clinics (both non-profit and for-profit) are abundant. Pharmacies and informal drug shops, often staffed by shopkeepers without pharmaceutical or medical training, are also widespread.

However, our study findings show significant barriers to accessing services in peri-urban townships. Our service mapping exercise highlighted disparities in service availability between facilities, a finding reiterated in our FGDs and interviews. Where reproductive health services were often geographically available, access was often hindered by other factors - for instance, varying opening hours, availability of products and services, and costs. While most hospitals are open 24 hours a day, they are relatively few in number. Meanwhile, the hours of operation of private clinics varied widely; most were open into the evening ( $\mathrm{n}=15$ out of 16 ), but less than a third remained opened throughout the entire day $(n=5)$. Further, the overall availability of reproductive health services and products appears varied and unpredictable. For instance, while the majority of public and private facilities stock Depo-Provera injections ( $\mathrm{n}=26$ out of 27), less than half offer condoms or emergency contraception, while long-acting reversible contraceptives like the IUD or implant are rarely available. Compared to clinics, hospitals offer a more comprehensive range of sexual and reproductive health services but costs vary tremendously; the limited number of public hospitals offered nominally free-of-charge services (although often with high, hidden costs), whereas private hospitals charged significant fees for consultation and medications/devices. Our participants' often characterized reproductive health care and services as expensive, but many knew that cheaper services and products could be accessed from NGOs.

Our participants characterized the public sector hospitals as expensive and inaccessible. Hospitals are often geographically distant from women's homes, and the few available transportation options mean an expensive taxi ride is often required to reach a facility, making these hospitals costly and time-consuming to access. Women were also deterred by the long wait times at overcrowded and understaffed pubic hospitals. We also found that a lack of information about which services hospitals provide and when they can be accessed deterred women from seeking care, particularly surrounding post-abortion care (reported in more detail in Sheehy et al., 2015). Fear of incurring significant expenses, like pressure to buy expensive medicines, was a significant deterrent to seeking care from the public sector.

The services available are a little distant from this area. Some go to the hospital, but they are afraid to go there 
because it may cost 10-20,000 kyat [USD10-20], and they will have to buy extra medicine every day... That is why they don't go to the hospital too much. They're afraid of the hospital. (30-year old resident of Insein township, FGD participant)

Despite the nominally free services offered by the public sector, many of our FGD participants preferred obtaining reproductive health services and products from private clinics and informal drug shops, despite the associated out-of-pocket expenses. Private clinics include both for-profit and non-profit facilities run by non-governmental service delivery organizations like Marie Stopes International and Population Services International, and were characterized by our participants as being more geographically and economically accessible. NGO-operated clinics were often preferred by our participants for reproductive health services and products, due to their accessibility, minimal cost, and non-judgmental service provision. However, for peri-urban women who have highly mobile lifestyles and who lack the time or money to access the formal health care system, drug shops in particular offer the most affordable and convenient option.

Most of the people have big economic problems, so most cannot go to the hospital. People there wait for a long time. And in the private clinics, they have to give a lot of their money; even if it's not a lot of money, they cannot afford to go to the clinic. So they just seek health services from the drug shops. (Doctor working in Hlaing Thar Yar township, FGD participant)

However, key informants told us that shopkeepers lack medical or pharmaceutical training and often give incorrect information about the dose and administration of medications. Further, they described how a reliance on informal providers is changing the willingness of some to seek more formal care:

Because of the low level of education and income, people cannot spend money or are not willing to spend money on providers...they just want to go out and buy drugs from the shops and they will get prescriptions and advice from them. Only when they cannot treat or heal themselves with those drugs will they seek out something else. (Key informant, July 2014)

Access to services is also impacted by the livelihoods of many peri-urban women, who work long hours, are uninterested in or financially unable to prioritize their health, and who engage in work that requires extensive mobility. Our FGD participants also described how decision-making around health is further influenced by socialized gender roles, the influence of a woman's husband or mother-in-law, religious considerations, the weight given to long-standing "traditional" beliefs and practices, and the advice of community elders, who hold considerable authority in peri-urban communities. These factors illustrate the strong influence of tradition - often more strongly held in rural regions - that characterizes the experiences and decision-making around health among peri-urban women in Yangon.

\subsection{Non-Evidence Based Fear of Contraceptive Side Effects Hinders Use}

The major issue is that due to lack of knowledge and information, they are afraid to use the contraception. (Key informant, June 2014)

Rampant misinformation, myths, and rumors appear to be one of the most significant barriers to the accessibility of reproductive health services in peri-urban Yangon, and particularly, to the accessibility of contraception. Although most of our FGD participants knew of various contraceptive methods, many held medically-inaccurate beliefs, and myths about contraceptive side effects were widespread. According to our FGD participants, as well as key informants, women's decision-making around family planning is largely influenced by what they hear from other women in their communities, especially respected elder women (known as aunties).

Although contraceptives are widely and cheaply available from pharmacies, drug shops, clinics, hospitals and NGOs, effective and continuous contraceptive use appears to be hindered by lack of information about which methods are available and where, misinformation about correct protocols for use, and non-evidence based or exaggerated fear of side effects. As one key informant explained, "Some of the young women, they're afraid [to] use the Depo injection... [They ask] "Will I become fat? Will people notice I am using [this method] by looking at my figure?" This concern about weight gain and distribution was echoed by women in our FGDs. Lack of information and fear of side effects also leads some women to be quick to attribute any illness or ailment to their contraceptive method, which can deter them from consistent and ongoing use.

Some women believe that whenever they suffer some minor illness, it is due to taking oral contraceptive pills, or taking Depo, or inserting the IUD. (Doctor working in North Okkalapa township, FGD participant).

Emergency contraceptive pills (ECPs) appear to be especially plagued by misinformation. Only half of participants in both the FGDs and our survey had heard of ECPs. Those who were aware of ECPs often confused them with abortifacients and knowledge about dose and timeframe for use was poor. Rumours about the potential 
risks associated with ECPs, particularly if used multiple times, appear rampant and included concerns about organ damage, infertility, and death.

You can only take it [ECPS] six times - if more than six times, there will be negative consequences, because that pill is so strong it can affect the uterus and you cannot have kids anymore. (29 year-old resident of North Okkalapa township, FGD participant)

Given the highly mobile nature of many peri-urban residents' livelihoods, ECPs could provide an important contraceptive option. However, this misinformation has contributed to overall lack of use; none of our FGD participants and only 6 out of 147 survey respondents (4\%) reported ever using ECPs. The need to expand access to comprehensive and reliable contraceptive information was unanimously identified as a priority among our FGD participants.

\subsection{Unmarried Women Are Excluded from Reproductive Health Care and Services}

I am single so I don't know much about reproductive health. (21 year-old, Insein township).

Respondents in all components of our study confirm that there is an absence of sexual and reproductive health services targeting unmarried women and adolescents as most existing services are geared exclusively to married women. As one key informant explained, "Here, when you see reproductive health, it's meant for married women... The young women think "it's not for me", so most of them just buy drugs over the counter." Although not unique to the peri-urban setting, this finding is relevant to reproductive health service delivery both within and beyond the study area. Our participants reported that both unmarried and young women are met with discrimination, judgment, and shame when they attempt to access care. The unmarried women in our FGDs generally had less reproductive health knowledge than our married participants, and frequently suggested that they did not have anything to contribute because they were single. They also reported discrimination when seeking reproductive health information or services. This finding was consistent with reports from our key informants. As one noted, "It's still very hard for a young woman to get a condom at the pharmacy. They will look down on you and surely talk behind your back like you're a bad girl." As a consequence, many unmarried and young women appear to bypass the health system entirely, obtaining products from drug shops or through male partners or married peers.

As I am married, I just go and buy it [emergency contraception] for her, because she is single. Single women don't buy it, just their boyfriends will buy it for them, or they will ask somebody they know. (26 year-old resident of North Okkalapa, FGD participant)

Although our findings suggest that use of ECPs is limited, many of our FGD participants who had heard of ECPs believed them to be exclusively used by young and unmarried women. Key informants explained that young and unmarried women may be more likely to use ECPs because they can more easily access the medication from drug shops without visiting a clinic or healthcare providers.

Going to the reproductive health clinic and asking for contraceptives is something only married women will do in our country. So unmarried, young women, they just use short-term methods like emergency contraception. (Key informant, June 2014)

Study participants also noted a lack of information and educational resources for unmarried and young women. According to our participants, including key informants and women in our FGDs, health service providers and community members are often hostile toward unmarried women who ask questions or evince knowledge of reproductive health. Some of our key informants who are involved in programming that tries to reach young women, highlighted how a woman's family can serve as a barrier to her accessing reproductive health services and information.

We organized an awareness training on sexual and reproductive health, but mothers don't want their daughters to attend, because they're worried that if they know about contraceptives, they will... have sex. So it's because of cultural and social issues that young women don't know about contraception. (Key informant interview, June 2014)

Our FGD participants and key informants repeatedly reported that the lack of information and services available to young and unmarried women hinders their ability to access reproductive health care and services, and specifically contraception. However, a growing interest in developing reproductive health services and programming tailored toward adolescents is evident.

\section{Discussion}

Neither fully urban nor fully rural, peri-urban populations straddle multiple worlds. In Yangon, the peri-urban 
population has a significant number of internal migrants; of our study participants, approximately one-third had migrated to peri-urban Yangon in recent years. The traditions, cultures and practices that often originate and are held more strongly in rural settings significantly influence the cultures of peri-urban communities, and must contend with the area's urban proximity, which brings with it better access to information, services and technologies. Together, these factors contribute to a dynamic set of circumstances that make this population unique, and "hard to reach" in unique ways. A concept historically used to describe geographically remote regions, peri-urban populations are forcing a redefinition of the concept of "hard to reach." While most peri-urban townships are geographically proximate to Yangon's city center, socioeconomic factors, including poverty, long work hours, and reliance on traditional practices, make this area hard to reach in a less geographic or spatial way. Indeed, peri-urban populations in Yangon face multiple layers of challenges in accessing health services, and donors, providers, and policy-makers face their own challenges in reaching this population.

Given the dynamic circumstances surrounding the health of the peri-urban population of Yangon, our findings suggest that a tailored approach is required to meet these diverse reproductive health needs. Our findings reveal that, even when services are geographically available, the population faces continued and significant barriers to access. Several measures could be taken to increase accessibility; for instance, expanding ferry transportation systems, which regularly bring groups to distant or otherwise inaccessible service delivery points, could significantly improve women's access to reproductive health care. Further, expanding access to information about the location and hours of facilities, as well as the services they provide, could mitigate the barriers that inconsistent opening hours present and ensure women are aware of where and when they can access care within their townships. Additional resources on the correct use of medicines like ECPs could help counteract the inaccurate advice given by ill-informed drug shop staff. Initiatives to increase access to information and create new programs should be developed in close consultation with community members to ensure they are culturally resonant and locally appropriate.

In addition to working to improve general service accessibility, there is a pressing for tailored, comprehensive reproductive health education resources for unmarried and young women, as well as low-literacy peri-urban populations. The stigma surrounding pre-marital sex, and the fact that reproductive health services, information, and resources are all exclusively targeted toward married women, means that unmarried women lack access to reliable and comprehensive reproductive health resources. The development of resources tailored toward unmarried populations could help ensure they have accurate, comprehensive, and non-judgmental sources of information.

Participants in our FGDs received much of their health information by word-of-mouth, and often based their health-related decision-making on the experiences and stories of family, friends, and neighbors. The advice of community elders is often prioritized over that of medical professionals, even when that advice is medically inaccurate. Low levels of literacy, and lack of easily accessible resources, may impede peri-urban women from seeking out alternate sources of information. Culturally appropriate resources, tailored toward community elders, could help ensure that the advice they share is accurate and comprehensive. Similarly, low-literacy materials, including graphic or pictoral handouts and radio broadcasts, could provide alternate sources of information for women who may otherwise depend on receiving health information from friends and family.

In contrast, although overall connectivity remains low, the recent expansion in access to mobile phones and the internet in the country could also provide new opportunities for disseminating health information, especially to youth. Myanmar has moved from one of the least connected countries in the world in 2013, to having a 75-80\% government target for national mobile coverage by 2016 (Beaufort Securities, 2015). Burmese-language resources developed for mobile or internet platforms have the potential to have reach across the country and provide accurate and comprehensive reproductive health information in an anonymous forum. Thus, a two-tiered health education approach that focuses on developing both low-literacy and high(er) tech resources appears warranted.

\section{Limitations}

Our study has several limitations. Perspectives from some peri-urban populations have not been reflected in our findings due to time, financial, and logistical constraints such that participants in our FGDs and surveys resided in only six of the nine peri-urban townships. Further, we did not collect information on ethnicity in our focus groups, interviews or surveys; given the small project sample, we did not feel data on ethnicity would provide any credible conclusions to draw upon. However, future research would benefit from an exploration of this dimension of socio-demographic identity. Finally, although our multi-disciplinary, multi-national team collaborated extensively on this project, working in multiple languages can present challenges. We appreciate 
that some nuance may have been lost in translation but we are confident that through team discussions and collaborative efforts we were able to accurately capture the perspectives of our participants.

All of our FGD and survey participants were affiliated with a local NGO or CBO, which was how we were able to recruit them. Subsequently, their knowledge of reproductive health and access to services is likely to be better than the peri-urban population as a whole. Finally, we used a convenience sample for the general reproductive health survey with participants from a microfinance program. The findings from the survey are not meant to be representative of the peri-urban population, but instead provide a snapshot of reproductive health outcomes among a selected peri-urban population. We believe that through the use of rigorous methods and triangulation of the findings, our results offer an important picture of reproductive health needs in peri-urban Yangon.

\section{Conclusion}

Our study findings illustrate that, despite an overarching availability of reproductive health services in peri-urban Yangon, a variety of geographic, socio-economic, information, and socio-cultural barriers to access persist and there remains a dearth of services tailored to young and unmarried women. This population requires a unique and tailored service delivery approach to meet their complex and varied reproductive health needs. As the peri-urban population in Yangon continues to expand the need for sound evidence will grow. The findings of this study may resonate with peri-urban populations in other large cities within Myanmar. Future research should continue to explore the reproductive health needs and health outcomes of peri-urban populations, within Myanmar and beyond.

\section{Acknowledgements}

This project was supported by a number of scholarships and grants, including a trainee grant from the Society of Family Planning, an Ontario Graduate Scholarship, and a travel scholarship from the University of Ottawa (GS). Dr. Foster's Endowed Chair is funded by the Ministry of Health and Long-Term Care in Ontario and we appreciate the general support for her time that made this project possible. Finally, Cambridge Reproductive Health Consultants' work in Thailand and Myanmar has long been supported by an anonymous donor to whom we are grateful.

The study team thanks all of the organizations and individuals who participated in the interviews, focus group discussions, and surveys. We would like to express our gratitude to the National YWCA of Myanmar, as well as the Yangon YWCA, for their support of the project and assistance with recruitment, facilitation, and translation. We also thank Drs. Raywat Deonandan and Shoshana Magnet for their feedback on earlier phases of this project. The conclusions and opinions expressed in this article are those of the authors and do not necessarily represent the views of the organizations with which the authors are affiliated or the funders.

\section{Conflict of Interest}

The authors declare that there is no conflict of interests regarding the publication of this paper.

\section{References}

Allen, A. (2010). Chapter 2: Neither rural nor urban: Service delivery options that work for the peri-urban poor. In M. Kurian \& P. McCarney (Eds.), Peri-urban Water and Sanitation Services: Policy, Planning and Method.

Ba Thike, K. (1997). Abortion: A public health problem in Myanmar. Reproductive Health Matters, 9, 94-100. Retrieved from http://www.rhm-elsevier.com/article/S0968-8080(97)90010-0/pdf

Back Pack Health Worker Team. (2006). Chronic emergency: Health and human rights in Eastern Burma. Retrieved from http://www.jhsph.edu/research/centers-and-institutes/center-for-public-health-and-humanrights/_pdf/ChronicEmergency_BPHWT_Report2005.pdf

Beaufort Securities. (2015). MySQUAR Ltd. Report. Retrieved from http://www.beaufortsecurities.com/videos /MySQUAR-Limited--3-_S.pdf

Brook, D. (2014). History of the present: Yangon. Places Journal. Retrieved from https://placesjournal.org/article/history-of-the-present-yangon-myanmar/

Burma Medical Association, National Health and Education Committee, \& Back Pack Health Worker Team. (2010). Diagnosis: Critical. Retrieved from http://www.jhsph.edu/research/centers-andinstitutes/center-for-public-health-and-human-rights/_pdf/Burma_DiagCritical_19Oct10.pdf

Chaw, C. (2003). Rural women migrating to urban garment factories in Myanmar, in Social Challenges for the Mekong Region. Chiang Mai University: Chiang Mai, Thailand. 
Davila, J. (2002). Rural-urban linkages: Problems and opportunities. Espaco \& Geografia, 2(35), 64.

De Jong, G. F., \& Gardner, R. W., (Eds.) (1981). Motivations for migration: An assessment and a value-expectancy research model. In Migration decision making: multidisciplinary approaches to microlevel studies in developed and developing countries. New York: Pergamon.

Department of Population. (2014). Population and housing census of Myanmar, 2014: Provisional results. Nay Pyi Taw, Myanmar. Retrieved from. http://unstats.un.org/unsd/demographic/sources/census/2010_ phc/Myanmar/MMR-2014-08-28-provres.pdf

Deniz, N., \& Lincoln, Y. (Eds.). (2005). The Sage handbook of qualitative research. Thousand Oaks, California: Sage Publications.

Elo, S., \& Kyngäs, H. (2008). The qualitative content analysis process. Journal of Advanced Nursing, 62(1), $107-115$.

Forbes Asia. (2014). Two telecoms race to wire in Myanmar. Forbes Asia: Special Reports, June 25, 2014. Retrieved from http://www.forbes.com/sites/forbesasia/2014/06/25/two-telecoms-race-to-wire-myanmar/

Gedeon, J., Nanda Hsue, S., Walsh, M., Sietstra, C., MarSan, H., \& Foster, A. (2015). Assessing the experiences of intra-uterine device users in a long-term conflict setting: A qualitative study on the Thailand-Burma border. Conflict and Health, 9(6).

Hlaing, K. Y. (2012). Understanding recent political changes in Myanmar. Contemporary Southeast Asia, 34, 197-216.

Hobstetter, M., Walsh, M., Leigh, J., Lee, C., Sietstra, C., \& Foster, A. (2015). In rape cases we can use this pill: A multimethods assessment of emergency contraception knowledge, access, and needs on the Thailand-Burma border. International Journal of Obstetrics and Gynaecology, 130, E37-E41.

Hobstetter, M., Walsh, M., Leigh, J., Lee, C. I., Sietstra, C., \& Foster, A. (2012). Separated by borders, united in need: An assessment of reproductive health on the Thailand-Burma border. Cambridge, MA: Ibis Reproductive Health. Retrieved from: http://www.ibisreproductivehealth.org/sites/default/files/files/publications/separatedbyborders-English.pdf

Iaquinta, D. L., \& Drescher, A. W. (2000). Defining periurban: Understanding rural-urban linkages and their connection to institutional contexts. Paper presented at Tenth World Congress of the International Rural Sociology Association, Rio de Janeiro, Brazil.

Macdonald, C., \& Thiha Cho, P. (2016). Rapid migration and lack of cheap housing fuels Yangon slum growth. Mizzima, News from Myanmar. February 20, 2016. Retrieved from http://mizzima.com/latest-news-newsfeatures/rapid-migration-and-lack-cheap-housing-fuels-yangon-slum-g rowth

Marshall, F., Waldman, L., MacGregor, H., Mehta, L., \& Randhawa, P. (2009). On the edge of sustainability:Perspectives on peri-urban dynamics, STEPS Working Paper 35, Brighton: STEPS Centre

Ministry of Immigration and Population and UNFPA. (2009). Country report on 2007 Fertility and Reproductive Health Survey. Nay Pyi Taw, Myanmar.

Ministry of Health and UNICEF. (2011). Myanmar multiple indicator cluster survey 2009-2010.

Mullany, L. C., Lee, C. I., Yone, L., Paw, P., Shwe Oo, E. K., Maung, C., Lee, T. J., \& Beyrer, C. (2008). Access to essential maternal health interventions and human rights violations among vulnerable communities in eastern Burma. PLoS Medicine, 5(12), 1689(10).

Mullany, L. C., Lee, C. I., Paw, P., Shwe Oo, E. K., Maung, C., Kuiper, H. ... Lee, T. J. (2008). The MOM project: Delivering maternal health services among internally displacd populations in Eastern Burma, Reproductive Health Matters, 16(31), 44-36.

Myanmar Information Management Unit [MIMU]. (2012). Yangon Region. Retrieved from http://www.themimu.info/sites/themimu.info/files/documents/Region\%20Map_Tsp_Yangon_MIMU693v02 _23\%20Feb\%2012_A1.pdf

Sheehy, G., Aung, Y., \& Foster, A. (2015). 'We can lose our life for the abortion': Exploring the dynamics shaping abortion care in peri-urban Yangon, Myanmar. Contraception, 92, 475-481.

Sietstra, C. (2012). The Thailand-Burma border: Addressing needs in long-term conflict settings. In A. M. Foster, \& L. L. Wynn (Eds.), Emergency Contraception: The story of a global reproductive health technology (pp. 


\section{9-253). New York: Palgrave MacMillan.}

Thin Zaw, P. P., Liabsuetrakul, T., Htay, T. T., \& McNeil, E. (2012). Equity of access to reproductive health services among youths in resource-limited suburban communities of Mandalay City, Myanmar. BMC Health Services Research, 12(458).

Thin Zaw, P. P., Liabsuetrakul, T., McNeil, E., \& Htay, T. T. (2013). Gender differences in exposure to SRH information and risky sexual debut among poor Myanmar youths. BMC Public Health, 13(1122).

Tun, W. M. (2014). Yangon MP calls on Myanmar government to rein in runaway rents. Radio Free Asia. Retrieved August 28, 2014, from http://www.rfa.org/english/news/myanmar/rent-08272014164933.html

UNFPA. (2010). Report on situation analysis of population and development, reproductive health and gender in Myanmar. Retrieved from http://yangon.sites.unicnetwork.org/files/2013/05/july-2010-Report-on-SituationAnalysis-UNFPA.pdf

Vallikappen, S., \& Thakur, P. (2013). Yangon more expensive than NYC sparking boom: real estate. Bloomberg Businessweek. Retrieved July 30, 2013, from http://www.bloomberg.com/news/2013-07-29/yangonmore-expensive-than-nyc-sparking-boom-real-estate.html

World Bank. (2014). Press Release: Myanmar moves toward connectivity for all. The World Bank: News. Retrieved February 6, 2014, from http://www.worldbank.org/en/news/press-release/2014/02/06/myanmarmoves-toward-connectivity-for-all

World Bank. (2013). Maternal mortality ratio (modeled estimate per 100,000 live births): Myanmar. Retrieved from http://data.worldbank.org/indicator/SH.STA.MMRTwww.cwds.ac.in/library/collection/elib/abortion /ab_abortion_a.pdf

\section{Copyrights}

Copyright for this article is retained by the author(s), with first publication rights granted to the journal.

This is an open-access article distributed under the terms and conditions of the Creative Commons Attribution license (http://creativecommons.org/licenses/by/3.0/). 